\title{
Formation of Ukraine's Climate Policy in the Context of European Integration
}

\author{
By Liudmyla Golovko, Olena Yara², Olena Uliutina ${ }^{3}$, Andrii Tereshchenko ${ }^{4}$, \\ Andrew Kudin ${ }^{5}$
}

\begin{abstract}
It is an indisputable fact that one of the most important problems today is global climate change. Climate change affects everyone and requires a concerted effort at regional, national and international levels. The most intensive legal regulation of environmental protection, including climate change, which has an extremely negative impact on the environment, is carried out on the European continent. The European Union is a leader in climate change prevention and an example for other countries. The state policy of Ukraine on legislative adaptation is formed as an integral part of legal reform in Ukraine and is aimed at ensuring common approaches to rule-making, mandatory consideration of European Union legislation in rule-making, training of qualified specialists, creating appropriate conditions for institutional, scientific, educational, technical, financial support of the process of adaptation of the legislation of Ukraine. In the scholarly work global and European trends in climate change prevention policy were revealed. The adaptation of Ukrainian legislation in the field of climate change to EU law was analyzed. The conceptual foundations of the environmental policy of Ukraine in the context of climate change were considered. The challenges and problems on the way to the implementation of climate policy were determined.
\end{abstract}

Keywords: climate change, environmental protection, legal regulation, adaptation of Ukrainian legislation to EU climate change law, the right to a fair trial

\section{Global Trends in Climate Change Prevention Policy}

At the international level, attention began to be paid to climate change in the second half of the 20th century. During a conference in Stockholm in 1967, the foundations of a program for the study of global atmospheric processes were developed. The 1979 World Climate Conference in Geneva laid the foundations for the World Climate Program. States recognized the need for international cooperation in mitigating climate change and developing effective means of prevention of global warming. In June 1992, the UN Framework Convention on Climate Change was adopted, the

\footnotetext{
| ${ }^{1} \mathrm{PhD}$., associate professor of the Department of International Law and Comparative Law of the National University of Life and Environmental Sciences of Ukraine

${ }^{2} \mathrm{PhD}$., professor of the Department of Administrative and Financial Law of the National University of Life and Environmental Sciences of Ukraine, Dean of the Faculty of Law of the National University of Life and Environmental Sciences of Ukraine

${ }^{3} \mathrm{PhD}$., professor of the Department of Administrative and Financial Law of the National University of Life and Environmental Sciences of Ukraine, Deputy Dean of the Faculty of Law of the National University of Life and Environmental Sciences of Ukraine

${ }^{4} \mathrm{PhD}$., director of Institute of Law and Social Relation, Open International University of Human Development "Ukraine"

${ }^{5}$ Doctor of Law, General Director of the State Enterprise "Ukrainian Institute of Intellectual Property.
} 
main purpose of which is to stabilize greenhouse gas concentrations in the atmosphere at a level that would prevent dangerous anthropogenic interference with the climate system. This level must be achieved within the time frame required for the natural adaptation of ecosystems to climate change, so as not to jeopardize food production and to ensure further economic development on a sustainable basis. The Convention requires the parties to take the following measures: to developm and implement national climate change mitigation programs; reporting on gas emissions; rational use of greenhouse gas sinks and storage facilities; promoting the exchange of scientific and other information related to climate change. This provides for the implementation of the requirements of the Convention in accordance with the individual conditions that exist within each state, i.e. the Convention provides for the implementation of more stringent requirements by developed countries than countries with economies in transition (United Nations, 1992). In the Kyoto Protocol, quantitative indicators were detailed for the obligations of states in the field of reduction of greenhouse gas emissions as a percentage of the base year, which is 1990. Annex A to the Protocol lists greenhouse gases that need to be reduced. One of the significant provisions of the Kyoto Protocol is the presence of so-called flexible mechanisms that contribute to the fulfillment of obligations imposed on states by receiving a certain income that can be used to invest in projects aimed at reduction of emissions. Such mechanisms are: joint implementation, which consists in financial assistance from one state to another in the implementation of a project aimed at reduction of greenhouse gas emissions, subject to further transfer of the received emission reduction units to the first state; the clean development mechanism, according to which states listed in Annex B can provide financial assistance in the implementation of climate change projects to countries not listed in Annex B, and use the results achieved on these projects; trading in quotas for greenhouse gas emissions - the parties listed in Annex B of the Protocol, in the event that they do not use the entire volume of permitted emissions, may sell them to the other Party (Bereznyuk, 2013).

The Paris Agreement replaced the Kyoto Protocol. According to it, all Parties must present their commitments to reduce greenhouse gas emissions through "nationally determined contributions" and set more ambitious goals in the next years. The parties assume nationally determined contributions when they ratify the Paris Agreement. The agreement includes requirements for all Parties to report regularly on the level of emissions and on efforts to meet their commitments. The global review of the implementation of nationally determined contributions, adoption of more ambitious nationally defined contributions and the assessment of collective progress towards the goal of the Agreement will take place regularly, every 5 years starting from 2025. Despite the abovementioned, the Paris Agreement has weak compliance mechanisms and does not provide for sanctions (Andresen, 2016).

Prevention of climate change is also facilitated by the activities of international institutions. Thus, in 1988 the World Meteorological Organization and the United Nations Environment Program established the Intergovernmental Panel on Climate Change, the main task of which is to carry out an objective assessment of scientific, technical and socio-economic information on climate change, its potential impact, risk assessment of human activity, as well as opportunities to avoid them. Each year Intergovernmental Panel prepares a report on the state of the climate. According to the 
report of 2018, humanity has about 10 years left before global changes lead to the first catastrophic consequences. In addition, in contrast to the Paris Agreement, experts call for limiting the growth of the average temperature not within $2{ }^{\circ} \mathrm{C}$, but within $1.5^{\circ} \mathrm{C}$ (IPCC, 2018).

Non-specialized international organizations also contribute to combating climate change. For example, the International Organization for Standardization, among other activities, promotes the development of standartization to help reduce, control and keep track of greenhouse gas emissions. A significant number of nongovernmental organizations are involved in the dissemination of information on climate change, but there is still a need to expand cooperation in the field of co-financing of climate programs.

\section{EU Climate Change Law}

Legislative initiatives of the European Union in the sphere of reduction greenhouse gas emissions into the air have been put forward since the $80 \mathrm{~s}$ of the twentieth century. The legal basis for the special regulation was created by Council Decision 2002/358/EC, by which the European Union ratified the Kyoto Protocol of 11 December 1997 and undertook to reduce greenhouse gas emissions by $8 \%$ in 1990 as a whole, by allocating commitments between its member states (Council Decision, 2002). In 2014, the European Council approved a new climate and energy policy until 2030, which presented newer, more ambitious goals for reduction of greenhouse gas emissions, improvement of energy efficiency and the use of renewable energy sources.

On July 20, 2015, the European Council adopted Conclusions on climate diplomacy, where climate diplomacy was defined and instructions on how different officials should develop policies in the relevant field, taking into account the problems of climate change were determined. Such a document is lacking in Ukraine, which is one of the reasons why the country's climate change prevention processes are so slow. Climate policy requires integration at different levels and cooperation between different government agencies and officials.

Energy 2020: A Competitive, Clean and Secure Energy Strategy enhances the integration of European energy markets with established standards and targets for reduction of greenhouse gas emissions, contributes to increasing energy efficiency and the share of renewable energy sources in the energy consumption structure.

Directive № 2010/75/EU on industrial emissions (integrated pollution prevention and control) requires the use of the integrated permitting system for emissions listed in Annex I thereto. The integrated permitting procedure requires authorities to apply an integrated assessment of the impact of the facility / activity on the environment and human health in general. The advantages of such a system are as follows: it allows when issuing a permit for environmentally hazardous activities to choose a method of its implementation that would take into account local environmental conditions; it allows the best of environmentally or technically possible ways of carrying out planned activities in terms of its impact on the environment; it allows to counteract the transfer of emissions between different environmental objects. For the purpose of ensuring a high level of environmental protection as a whole Article 11 of the Directive requires the best available technologies or methods of carrying out the activities listed in Annex I to the 
Directive. The Directive also requires that the procedure for issuing an integrated permit should be transparent. The transparency of the integrated permitting procedure is ensured by the participation of the interested public. Such participation consists in the possibility of submission of comments and suggestions to the application for an integrated permit, which the permitting authority is obliged to take into account (Directive № 2010/75/EU).

The basis of the preventive and stimulating mechanism of climate protection is the widespread use of renewable energy, which is the subject of regulation of Directive $2009 / 28 / \mathrm{EC}$ on the use of energy from renewable sources. According to this Directive, by 2020 the share of renewable sources in the European Union should be $20 \%$ of total energy consumption, including $10 \%$ in the transport sector. States must calculate their target share of renewable energy in accordance with the rules of Articles $5-11$ of the Directive, and define it in the national renewable energy action plan together with the implementation procedures. By providing some flexibility in fulfilling the obligations, the Directive allows the exchange of renewable energy quotas and the implementation of joint projects by EU member states among themselves and with third countries (Articles $6-11)$. In order to confirm the fulfillment of obligations, states provide a guarantee of the origin of energy from renewable sources, as it is prohibited to use biofuels that do not meet the "sustainability criteria" for the purposes of the Directive. The new plants, which came into operation on January 1, 2008 and produce biofuels for transport, electricity, heating or cooling, should reduce greenhouse gas emissions by $35 \%$ compared to traditional fuels. The implementation of the Directive is ensured by the national legislation of the EU countries by introducing a procedure for environmental certification of biomass and audit of activities related to the procurement, production, processing and supply of biological raw materials. The requirements of Directive $2009 / 28 / \mathrm{EU}$ are applied to biofuels produced in third countries, therefore states importing biofuels to the EU must meet sustainability criteria as well (Directive 2009/28/EC).

The European Emissions Trading Scheme is recognized as one of the central ways of reduction of emissions, as it concerns more than 11,000 pollutants, which account for about $40 \%$ of the EU's greenhouse gas emissions. Pursuant to Directive 2003/87/EC, the system became operational on January 1, 2005, before the entry into force of the Kyoto Protocol. It obliges EU Member States to ensure that, from January 1, 2005, no source or installation will emit greenhouse gases from any of the objects / activities listed in Annex I without a permit issued by the competent authorities (Article 4) (Directive 2003/87/EC).

Aimed primarily at CO2 emissions in the energy sector, Directive 2003/87 / EC, as amended by Directive 2009/29/EC, has extended its scope to new activities (capture, transport and geological disposal of carbon dioxide, air transport, aluminum production, chemical industry), and other, except CO2, greenhouse gas emissions. The system is based on the principle of "cap-and-trade", which is based on the mechanism of emissions trading under the Kyoto Protocol. In particular, the basis for issuing an emission permit is a national allocation plan for national greenhouse gas emissions, which is provided by the state to the EU Commission for approval. Conditions for the distribution of permits are defined in Art. 9-11 and Annex III of the Directive. 
Exceeding the permitted amount of emissions by the operator entails the application of sanctions in the form of publication of the names of violators and a fine for each metric ton of CO2 equivalent. Harmonized conditions for the free permits, which can be transposed into the legislation of EU member states have also been adopted. From January 1, 2013, free allocation of permits will take place in accordance with the principle of benchmarking, which is based on the ratio of CO2 emissions per unit of output or energy, provided the best of existing technologies for each industry or subsector. The operator of equipment that does not meet these indicators acquires the required number of permits on the auction. The conditions for selling permits have also been changed. Starting from 2013, all permits that are not granted for free are subject to sale at auction fulfilling the requirements prescribed by Article 10 and the Annexes to the Directive. In general, it is envisaged that the total number of permits will be reduced linearly by at least $1.74 \%$ per year and the issuance of such permits will be suspended in 2027 . According to scientists, the advantage of the Directive is that it obliges states to use at least $50 \%$ of the proceeds from the sale of permits for environmental activities at auction (Prokhorenko, 2013).

In December 2019, the European Commission presented a large-scale program, the goal of which is to transform the European Union into a carbon-neutral continent - the European Green Deal. This program covers all areas of economic life and aims to create a new growth strategy that seeks to transform the EU into a just and prosperous society with a modern resource-efficient and competitive economy. The Commission proposes to reduce emissions by $50 \%$ or $55 \%$ by 2030 compared to 1990 level. It is planned to reduce the total emissions by $2.2 \%$ annually (European Comission, 2019). The goals are certainly ambitious and require significant efforts on the part of EU member states.

\section{Adaptation of Ukrainian Legislation in the Field of Climate Change to EU Legislation}

By signing the Association Agreement with the EU, Ukraine has undertaken the following commitments in the field of climate change: development of a long-term action plan to mitigate climate change, development and implementation of long-term measures to reduce greenhouse gas emissions, use of sources of renewable energy and energy-saving products and services, development of sectoral strategies on air quality, industrial pollution and industrial accidents, development of financial strategies to attract investment in infrastructure and technology, development of a comprehensive environmental strategy that will include planned institutional reforms to ensure the implementation and enforcement of environmental legislation, promote the integration of environmental policy into other areas of state policy, identify the necessary human and financial resources. The tasks facing Ukraine are ambitious and require significant political, economic, technical, organizational and other legal measures on the part of the state. However, it should be noted that the first steps have already been taken. The following documents were developed and adopted: the Concept of the state policy in the field of climate change for the period till 2030, the Plan of measures for its implementation, the National plan of reduction of emissions of large combustion plants which approves measures on gradual reduction of emissions of sulfur dioxide, nitrogen 
oxides and substances in the form of suspended solids, undifferentiated by composition (dust), Low Carbon Development Strategy until 2050, the Law of Ukraine "On Principles of Monitoring, Reporting and Verification of Greenhouse Gas Emissions", Energy Strategy for the period up to 2035 "Security, Energy Efficiency, Competitiveness". These documents are designed to address the following problems inherent in Ukraine: the lack of a systematic approach to climate change in general, the need to improve the legal framework of climate change, insufficiently clear division of powers between public authorities, low level of coordination of public authorities in planning and implementing the policy in the field of climate change prevention, insufficient awareness of civil society and public authorities with all aspects of the problem of climate change and low-carbon development.

In order to implement the Paris Agreement in the context of sustainable, climate-friendly development, Ukraine plans not to exceed $60 \%$ of greenhouse gas emissions in 2030 from the level of emissions of such gases in the base year 1990. Given the economic downturn in Ukraine compared to 1990, Ukraine may do nothing to prevent climate change to meet its goals. Concerning real greenhouse gas emissions in Ukraine, today they account for about 40\% of 1990 emissions. Therefore, the goals in the field of reducing greenhouse gas emissions in Ukraine cannot be considered ambitious.

The Law of Ukraine "On Environmental Impact Assessment" establishes that the environmental impact assessment procedure provides a description of the impact of planned activities on climatic factors, including climate change and greenhouse gas emissions. One of the main problems of environmental impact assessment in Ukraine is the imperfection of the adopted law regulating legal relations in this area. This is confirmed by a number of scientific studies (Krasnova, 2020; Kachur, 2020; Kutsevych, 2020; Shparyk, 2018; Tarasova, 2018; Yara, 2021), as well as the practice of application of this Law. The Law does not precisely regulate the conduct of environmental impact assessment. Article 6 of the Law, which is devoted to this question, only determines the general structure of the report on environmental impact assessment, and in no way regulates the actual preparation and assessment of the quality of the report, does not contain information on criteria (indicators) for environmental impact assessment, the rights and obligations of customers and executors of the report during public discussion of the planned activities. Also, the law does not prescribe the procedure for holding public hearings, which leads to arbitrary interpretation and implementation of their holding.

In Ukraine there is a positive trend towards more intensive use of renewable energy sources (Gulac, 2019; Khomyachenko, 2019; Ladychenko, 2018; Shulga, 2020). However, there are number of problems preventing the development of this sphere: instability of business environment; lack of financing; difficulties in financing projects in the sphere of renewable energy; limited competition in the field of renewable energy; high level of corruption in the licensing system; lack of maps and atlases to mark potential renewable energy sources of sun and wind; imperfect legal regulation of issues related to land acquisition for renewable energy facilities; small number of competent and highly qualified specialists in the field of renewable energy. The main problem of financing of energy sector in Ukraine is primarily related to the absence sources of longterm bank loans. In world practice, energy companies are able to attract cheap long-term 
loans for modernization and construction of new facilities, instead in Ukraine, except of a few major players, they are deprived of such possibility. Secondly, existing tariffs for renewable energy does not allow producers to accumulate funds for investment programs. The third factor is insufficient demand for Ukrainian energy assets from the side of foreign strategic investors. This is due to a high risk of investing in Ukraine, and necessity to compete with Ukrainian financial-industrial groups, which have more opportunities to defend their interests in this sector (The energy sector of Ukraine, 2013). It is also worth noting that a major obstacle to the dynamic development of renewable energy in Ukraine is the imperfection of the legislative framework for the functioning of the industry. The main documents regulating energy development in Ukraine are the Laws of Ukraine "On electricity", "On Alternative Energy Sources", "On principles of functioning electricity market of Ukraine", "On energy saving", "On regulation of urban development". These documents are ineffective because they do not contain clear algorithm for the use of renewable energy. In addition, they lack the popularization of renewable energy sources among the population and enterprises of Ukraine.

\section{Conclusions}

International agreements aimed at combating climate change set the goal, tools and means of overcoming global warming. Although they are not effective enough (weak enforcement mechanisms, lack of sanctions), they are tangible evidence of states' efforts to prevent climate change. At the same time, it should be noted that there is the need for more cooperation in financing and technology exchange between countries in order to achieve a common goal.

Considerable attention is paid to climate protection in the EU. The work within the framework of the EU Climate Program, which began in 2000, contributed to the identification of the most environmentally and economically effective ways to reduce greenhouse gas emissions, which formed the basis for the development of an extensive system of EU legislation in the following main areas: monitoring of anthropogenic emissions and absorption of greenhouse gases; European Emissions Trading System; reduction of emissions in the field of energy (energy saving, energy efficiency, renewable energy sources); development of innovation and low-carbon technologies; reduction of emissions in sectors not covered by emissions trading (waste, transport, construction, agriculture); special measures to limit fluorinated greenhouse gases; adaptation to climate change; sustainable management of land and forest resources.

Ukraine has adopted the first regulations in the field of climate change prevention, but their implementation in practice is not effective enough. The reason is energy-intensive production with low added value, lack of implementation of clean technologies and energy saving measures. Following the example of the EU, Ukraine needs to draw conclusions on climate diplomacy, which would stipulate that climate change is a priority in the formulation of public policy in various areas and should contain clear guidelines on how different officials should develop policy in this area. Climate policy needs integration at different levels.

Although some steps have been taken in Ukraine to reduce air emissions, there is no 
improvement in air quality. The public began to get acquainted with the state of the air. Interactive maps with air quality indicators and major sources of air pollution have appeared on the Internet, but no practical steps have been taken to reduce emissions from these sources. There are cases when, although the environmental protection body became aware of the excess of permitted emissions by individual enterprises as a result of the environmental expertise, they do not take any actions to stop the violation of environmental legislation by these bodies. This state of affairs is possible due to the insufficient amount of authority vested in environmental inspectorates. On the example of EU member states, it is necessary to ensure the possibility of environmental inspectorates to temporarily suspend the activities of enterprises in case of violations of environmental legislation and causing damage to the environment.

Environmental impact assessment, as one of the means of ensuring environmental safety, is one of the expert assessment measures of such a system. Its main purpose is to prevent environmental damage, ensure environmental protection, climate change prevention, rational use and reproduction of natural resources in the decision-making process of economic activities that may have a significant impact on the environment, taking into account public and private interests. Therefore, its legal regulation must be detailed and cannot lead to arbitrary interpretation during the implementation of its individual stages.

\section{References}

Andresen, P., Skjærseth, J., Jevnaker, T., Wettestad, J. (2016). The Paris Agreement: Consequences for the EU and Carbon Markets? Politics and Governance, 4 (3), 188-196.

Bereznyuk, T.V. (2013). Features of application of framework agreements in international legal regulation of climate change. Foreign trade: economics, finance, law, 5-6, 188-191.

Council Decision 2002/358 of 25 April 2002 concerning the approval, on behalf of the European Community, of the Kyoto Protocol to the United Nations Framework Convention on Climate Change and the joint fulfillment of commitments thereunder. OJ L 130. 2002. p. 1-3.

Directive 2003/87/EC of the European Parliament and of the Council of 13 October 2003 establishing a scheme for greenhouse gas emission allowance trading within the Community and amending Council Directive 96/61/EC (Text with EEA relevance), OJ L 275, 25.10.2003, p. 32-46

Directive 2009/28/EC of the European Parliament and of the Council of 23 April 2009 on the promotion of the use of energy from renewable sources and amending and subsequently repealing Directives 2001/77/EC and 2003/30/EC. OJ L 140. 5.6.2009. p. 16-62.

Directive 2010/75/EU of the European Parliament and of the Council of 24 November 2010 on industrial emissions (integrated pollution prevention and control) Text with EEA relevance, OJ L 334, 17.12.2010, p. 17-119

European Comission. 2050 long-term strategy. (2019). https://ec.europa.eu/clima/policies/strategies/2050_en

European Comission. EU emissions trading systems (EU ETS). (2020). https://ec.europa.eu/clima/policies/ets_en

Golovko, L. (2017) Implementation of EU Water Policy in Ukraine: Problems and Perspectives. Proceedings of the $8^{\text {th }}$ International Scientific Conference Rural Development, pp. 605-610

Golovko, L., Kutsevych, M., Serediuk, V., Bogdan, O. (2020). Implementation of EU Environmental Policy in Ukraine: Directions and Perspectives. European Journal of Sustainable Development, Volume 9, № 4, 191-198.

Golovko, L., Yara, O., Kutsevych, M., Hubanova, T. (2019). Environmental Policy Integration in Ukraine and the EU. European Journal of Sustainable Development, Volume 8, № 3, 221-227.

Gulac O.V., Goloviy L.V. (2019). Topical issues of formation state anti-corruption policy in Ukraine. The institutionalization of public relations in the fight against corruption: the experience of countries 
of Eastern and Western legal traditions (universal theoretical framework for relevant anticorruption law of Ukraine): Collective monograph. Volume 1. Tallinne: Izdevnieciba "Baltija Publishsng", 197-214.

Gulac, O., Dubchak, L., Iarmolenko, I., Yanchuk, J. (2019). Cooperation of Ukraine and the European Union in the ecological sector: directions and prospects. European Journal of Sustainable Development, Volume 8, № 1, 22-30.

IPCC. Global Worming of $1.5^{\circ} \mathrm{C}$. IPCC Special Report. (2018). URL: https://www.ipcc.ch/sr15/

Kachur, V., Protosavitska, L., Zasukha, L., Golovko L. (2020). The Role of Legal Culture in Maintaining Social Stability and Countering Separatist Movements: Case of Ukraine. European Journal of sustainable development, Volume 9, № 1, 294-299.

Khomyachenko, S. (2019). Conformity of land relations to productive forces: retrospective analysis. EurAsian Journal of BioSciences Eurasia J Biosci, 13, 2119-2124.

Kidalov, S., Vitiv, V., Golovko, L., \& Ladychenko, V. (2020). Legal Regulation of Waste Management in Ukraine on the Way to European Integration. European Journal of Sustainable Development, 9(2), 422430.

Krasnova, Y., Golovko, L., Hunko, L., Medynska, N. (2020). Development of Legal Regulation of Land Ownership in Ukraine, Solid State Technology Volume: 63 Issue: 2s, 4087 - 4094. URL: http://www.solidstatetechnology.us/index.php/JSST/article/view/2570

Kutsevych , M., Yara, O., Golovko, L., \& Terpeliuk, V. (2020). Sustainable Approaches to Waste Management: Regulatory and Financial Instruments. European Journal of Sustainable Development, 9(2), 163-171.

Ladychenko, V., Golovko, L. (2018). The Right of Access to Environmental Information in Ukraine and the EU. European Journal of Sustainable Development, Volume 7, № 3, 455-459

Prokhorenko, K.A. (2013). Climate as an object of ecological and legal protection of Ukraine: abstract of the dissertation of the candidate of legal sciences. Kyiv, Taras Shevchenko National University of Kyiv.

Shparyk, N. (2018). Legal Regulation of Environmental Impact Assessment in Ukraine: Current State. Journal of V asyl Stefanyk Precarpathian National University, 5(2), 152-162.

Shulga, I., Kalayanov, D., Shynkaruk, O., Shytyi, S., \&amp; Ivanov, F. (2020). Introduction of Alternative Sources of Energy as a Tool for Provision of Environmental Human Rights. European Journal of Sustainable Development, 9(1), 141. URL: https://doi.org/10.14207/ejsd.2020.v9n1p141

Tarasova, O., Bondarenko, O., Sharavara, V., Protsiv, G., Gavrilyuk, R., Gulevets, D., Tymchenko, I., Savchenko, S., Gusev, O., Zhurbas, K. (2018). Problematic issues of the EIA procedure: analysis and proposals. Kyiv: NECU.

The energy sector of Ukraine. (2013). Research based on a survey of participants of sectoral market. URL: https://assets.kpmg.com/content/dam/kpmg/ua/pdf/2016/09/KPMG-Energy-Survey-2012.pdf

Towards a European Climate Change Programme (ECCP): Communication of 8 March 2000. COM 2000. 88 final. URL: https://eur-lex.europa.eu/LexUriServ/LexUriServ.do?uri=COM:2000:0088:FIN:EN:PDF

United Nations. (1992). What is the United Nations Framework Convention on Climate Change? URL: https://unfccc.int/process-and-meetings/the-convention/what-is-the-united-nations-frameworkconvention-on-climate-change

Yara, O., Brazheyev A., Golovko L., Bashkatova V. (2021). Legal Regulation of the Use of Artificial Intelligence: Problems and Development Prospects. European Journal of Sustainable Development, 10 (1), 281-289.

Yara, O., Uliutina, O., Golovko, L., Andrushchenko, L. (2018). The EU Water Framework Directive: Challenges and Prospects for Implementation in Ukraine. European Journal of Sustainable Development, Volume 7, № 2, 175-182. 